\title{
Assessment of electricity distribution business model and market design alternatives: Evidence for policy design
}

\author{
Guillermo Ivan Pereira 124 \\ Patrícia Pereira da Silva 123 \\ Deborah Soule 4
}

${ }^{1}$ Energy for Sustainability Initiative

MIT Portugal Program in Sustainable Energy Systems

University of Coimbra

Rua Luís Reis dos Santos, 3030-788, Coimbra, Portugal

gpereira@student.dem.uc.pt

${ }^{2}$ INESC Coimbra

Institute for Systems Engineering and Computers at Coimbra

Rua Sílvio Lima, Pólo II, 3030-290, Coimbra, Portugal

${ }^{3}$ CeBER, Centre for Business and Economics Research,

Faculty of Economics

University of Coimbra

Av. Dias da Silva, 165, 3004-512 Coimbra, Portugal

patsilva@fe.uc.pt

${ }^{4}$ Massachusetts Institute of Technology

77 Massachusetts Avenue, E94, Cambridge, MA 02139, USA

dsoule@dba2003.hbs.edu

\section{Funding}

The authors acknowledge the Portuguese National Found ation for Science and Technology (FCT) for supporting this work through the Doctoral Grant PD/BD/105841/2014, awarded on the framework of the MIT Portugal Program funded through the POPH/FSE.

Additionally, this work has been partially supported by FCT under project grant: UID/MULTI/00308/2013, and SAICTPAC/0004/2015-POCI-01-0145-FEDER-016434, as well as by the Energy for Sustainability Initiative of the University of Coimbra. 


\title{
Assessment of electricity distribution business model and market design alternatives: Evidence for policy design
}

\author{
Abstract \\ The transition toward smart electricity distribution grids is transforming the European \\ electricity sector. This has contributed to increased attention by policy makers regarding the \\ future role of electricity distribution system operators in a more flexible, digital, and \\ renewables based electricity system. A better understanding on how to support the \\ adaptation of the electricity distribution industry can contribute to the introduction of an \\ effective policy framework. Our research provides evidence for policy design by presenting \\ the results of a Policy Delphi study focused on business model and market design \\ adaptation alternatives. We highlight the importance of supporting innovation and a more \\ proactive approach to adaptation from both distribution system operators, and regulators. \\ Our findings support the importance of electricity distribution for neutral market \\ facilitation, contributing to market development and enabling new market players. The \\ results obtained support policy makers working on electricity sector adaptation and can \\ contribute to the ongoing market redesign efforts under the Energy Union.
}

Keywords

Smart grids, electricity distribution, policy adaptation, Policy Delphi, European Union, policy design, market design. 


\section{Introduction}

Delivering a modern and clean electricity sector has been a priority of European Union (EU) policies for a low carbon economy ${ }^{1-3}$. Smart electricity distribution grids contribute to this goal by supporting the integration of legacy network assets; distributed energy resources; and monitoring, automation, and control technologies. These enable system flexibility, resulting from the increase of variable renewable electricity sources, electric vehicles and their charging infrastructure, electricity storage units, and behind-the-meter energy management systems ${ }^{4-6}$. Nevertheless, the evolution toward smart distribution grids challenges the traditional role, activities, and responsibilities of electricity distribution system operators (DSOs) ${ }^{7,8}$. Bi-directional electricity flows, increasing shares of distributed loads connected to the grids, more engaged consumers, and the need for new approaches to network operation and management are a few of the causes driving attention to the role of the DSO in the future. Moreover, their operation as a regulated natural monopoly, and responsibility for neutral market facilitation increase the complexity of introducing new services, business models, and role changes at the distribution level.

Implementing policies that consider the possibilities resulting from the transition to smart grids and digitalisation, whilst ensuring a secure, reliable, and affordable service for European consumers is a complex market transformation effort. This has contributed to an increased focus from European policy makers, regulators, and the electricity distribution industry on understanding the future of electricity distribution. Resulting from these efforts the recent Clean Energy for All Europeans policy package proposed a new EU electricity market design. The policy proposals from the European Commission provide a perspective on the future structure and reforms to occur in the electricity sector.

Through this study, we aim to contribute to the ongoing process of policy design for a changing electricity distribution sector. We applied an expert elicitation method to obtain European experts' perspectives on policy alternatives related to business model adaptation and market design. The analysis of business model adaptation includes aspects related to business strategy, adaptation challenges, and tasks and responsibilities. The policy alternatives for market design include issues both at the Member State and at the EU level. Our research aims to contribute with evidence for policy design for EU electricity market transformation. In this article we focus on the experts' perspectives on the policy alternatives under analysis. Our findings combine qualitative feedback collected from the participating experts, with quantitative assessments.

The manuscript is organised as follows. Section 2 provides background information on market transformation and electricity distribution in the EU. Section 3 describes the research design implemented. Section 4 presents the obtained results. Section 5 discusses the findings and Section 6 concludes.

\section{Background}

\section{Market transformation under the Energy Union}

The ambition to provide reliable, affordable, and clean energy has been guiding the EU electricity sector market transformation process over the past two decades. Initially, 
structural changes focused on the institutional configuration of the electricity value chain. This resulted in the unbundling, privatization, and reorganisation of former vertically integrated utilities. Electricity transmission and distribution networks were established as natural monopolies and separated from electricity generation and retail to support market development and competition.

Recent market design efforts under the Energy Union build on the characteristics of a liberalised electricity sector and aim to establish a framework in which increasing shares of variable renewable energy, demand-side electricity resources, and digital technologies can be integrated to deliver a flexible electricity system. This can be observed as a smart and clean restructuring process ${ }^{9}$. The Energy Union supports market transformation by focusing on market integration; and research, innovation, and competitiveness ${ }^{10}$. Regarding market integration, legislative proposals for electricity sector market design were introduced under the Clean Energy for All Europeans policy package ${ }^{11}$. The proposed policies aim to adapt the directive on the common rules for the internal market in electricity ${ }^{12}$, the regulation on the internal market for electricity ${ }^{13}$, and the regulation establishing an Agency for the Cooperation of Energy Regulations ${ }^{14}$. These proposals consider the possibilities for DSOs to manage system flexibility more locally, as well as the importance of securing their neutral role in market facilitation for electricity suppliers and new market players.

In terms of research, innovation, and competitiveness, smart grids and digitalisation of distribution systems are a priority under the Strategic Energy Technology (SET) plan ${ }^{15}$. Under this plan a 10-year research and innovation roadmap was developed ${ }^{16}$. This aims to contribute for a transition in electricity distribution systems that enables distribution network upgrades, system flexibility and reliability, digitalisation, and new market designs and regulations. These priorities are supported through targeted research and innovation efforts. Table 1 presents the clusters and objectives defined for electricity distribution and the estimated investments needed. 
Table 1. Electricity distribution innovation and investments.

Source: 16

\begin{tabular}{|c|c|c|}
\hline Cluster & Objective & $\begin{array}{l}\text { Investment } \\
(\mathrm{M} €) \\
\end{array}$ \\
\hline \multirow{2}{*}{$\begin{array}{l}\text { Integration of smart } \\
\text { customers and } \\
\text { buildings }\end{array}$} & Active demand response & 124 \\
\hline & $\begin{array}{l}\text { Energy efficiency from integration with smart } \\
\text { homes and buildings }\end{array}$ & 139 \\
\hline \multirow{6}{*}{$\begin{array}{l}\text { Integration of } \\
\text { decentralised } \\
\text { generation, } \\
\text { demand, storage, } \\
\text { and networks }\end{array}$} & Integration of small distributed energy resources & 68 \\
\hline & $\begin{array}{l}\text { Integration of medium distributed energy } \\
\text { resources }\end{array}$ & 79 \\
\hline & Integration of storage in network operations & 100 \\
\hline & Infrastructure to host electric vehicles & 100 \\
\hline & Integration with other energy networks & 150 \\
\hline & $\begin{array}{l}\text { Integration of flexible decentralised thermal power } \\
\text { generation }\end{array}$ & 125 \\
\hline \multirow{4}{*}{ Network operations } & Monitoring and control of low voltage networks & 142 \\
\hline & $\begin{array}{l}\text { Automation and control of medium voltage } \\
\text { networks }\end{array}$ & 100 \\
\hline & Smart metering data processing & 100 \\
\hline & Cyber security & 100 \\
\hline \multirow{3}{*}{$\begin{array}{l}\text { Planning and asset } \\
\text { management }\end{array}$} & New planning approaches and tools & 100 \\
\hline & Asset management & 48 \\
\hline & Total estimated investment & 1475 \\
\hline
\end{tabular}

\section{Electricity distribution industry in the EU}

The Energy Union policy framework provides a common vision for implementing changes in the electricity sector that support the energy transition. However, this EU level strategy for market transformation is challenged by the existence of different regulations in each of the 28 Member States ${ }^{10}$, as well as a heterogeneous electricity distribution industry across countries. Table 2 provides a perspective on this heterogeneity and presents the number of DSOs, number of DSOs serving over 100,000 consumers, and the total number of connected consumers. 
Table 2. DSOs and connected consumers.

Source: ${ }^{17}$

\begin{tabular}{|c|c|c|c|}
\hline Country & $\begin{array}{l}\text { Number } \\
\text { of DSOs } \\
\text { in } 2011\end{array}$ & $\begin{array}{l}\text { Number of DSOs } \\
\text { with } \\
\geq 100,000 \\
\text { consumers in } 2011\end{array}$ & $\begin{array}{l}\text { Total number of } \\
\text { connected } \\
\text { consumers }\end{array}$ \\
\hline Austria (AT) & 138 & 13 & $5,870,000$ \\
\hline Belgium (BE) & 24 & 15 & $5,243,796$ \\
\hline Bulgaria $(\mathrm{BG})$ & 4 & 3 & $4,915,497$ \\
\hline Cyprus (CY) & 1 & 1 & 535,050 \\
\hline Croatia (HR) & 1 & 1 & $2,300,000$ \\
\hline $\begin{array}{l}\text { Czech Republic } \\
(\mathrm{CZ})\end{array}$ & 3 & 3 & $5,837,119$ \\
\hline Denmark (DK) & 72 & 6 & $3,277,000$ \\
\hline Estonia $(\mathrm{EE})$ & 36 & 1 & 652,000 \\
\hline Finland $(\mathrm{FI})$ & 85 & 7 & $3,309,146$ \\
\hline France (FR) & 158 & 5 & $33,999,393$ \\
\hline Germany (DE) & 880 & 75 & $49,294,962$ \\
\hline Greece (GR) & 2 & 1 & $8,195,725$ \\
\hline Hungary (HU) & 6 & 6 & $5,527,463$ \\
\hline Ireland (IE) & 1 & 1 & $2,237,232$ \\
\hline Italy (IT) & 144 & 2 & $31,423,623$ \\
\hline Latvia $(\mathrm{LV})$ & 11 & 1 & 873,856 \\
\hline Lithuania (LT) & 1 & 1 & $1,571,789$ \\
\hline Luxembourg (LU) & 6 & 1 & 265,000 \\
\hline Malta (MT) & 1 & 1 & 436,947 \\
\hline Netherlands (NL) & 11 & 8 & $8,110,000$ \\
\hline Poland (PL) & 184 & 5 & $16,478,000$ \\
\hline Portugal (PT) & 13 & 3 & $6,137,611$ \\
\hline Romania (RO) & 8 & 8 & $2,639,318$ \\
\hline Slovenia (SI) & 1 & 1 & 925,275 \\
\hline Slovakia (SK) & 3 & 3 & $2,392,418$ \\
\hline Spain (ES) & 349 & 5 & $27,786,798$ \\
\hline Sweden (SE) & 173 & 6 & $5,309,000$ \\
\hline $\begin{array}{l}\text { United Kingdom } \\
\text { (UK) }\end{array}$ & 7 & 7 & $30,828,266$ \\
\hline Total & 2,323 & 190 & $266,372,284$ \\
\hline
\end{tabular}

The EU electricity distribution industry is composed of 2,323 DSOs, of which 190 serve over 100,000 consumers. These larger DSOs have been mandated to unbundle their electricity distribution activities from other generation, transmission, and retail activities as part of the market liberalisation process ${ }^{18}$. Conversely, DSOs below this threshold can be 
exempted from unbundling, supporting economies of scale possible by aggregating other activities, such as water and gas distribution ${ }^{17}$. In terms of industry structure, it is possible to observe considerable differences in the number of DSOs across Member States. These differences are in general the result of historical, political and geographical characteristics of each country ${ }^{19}$.

Complementing the structural characteristics of electricity distribution, Figure 1a provides a perspective on DSO concentration, which measures the relationship between a country's DSOs and distributed power ${ }^{\text {a }}$. In general, EU Member States have a medium to low concentration level, with Croatia, Cyprus, Greece, Malta, Ireland, Lithuania, and Slovenia having a high concentration level.

From a regulatory perspective DSOs are natural monopolies and operate under the rules of National Regulatory Agencies. (NRAs) These establish the regulatory framework that simulates competition given that DSOs are not subject to competitive market forces, and control quality of service ${ }^{20}$. Figure $1 \mathrm{~b}$ offers a perspective of the regulatory mechanisms in place across the EU following Cambini's ${ }^{21}$ aggregation in cost-based models, hybrid models, and incentive models ${ }^{\mathrm{b}}$. EU countries are mostly applying a mix of incentive and hybrid regulatory approaches, with only Belgium, Croatia, Cyprus, Greece, and, Malta applying a cost-based model. The reduced number of countries applying a cost-based model can be explained considering the small incentives for cost reduction it induces, as well as the possibility for over investment under this type of regulation 21,22 .

Beyond the general regulatory framework implemented at each Member State Figure 1c provides information on the existence of innovation inducing mechanisms in a country's electricity distribution sector regulations. DSOs amidst the energy transition face challenges due to the integration of new technologies, consumers and producers' behaviours, and a changing market design. These changes require investments in new assets, and can entail new costs that are not familiar for DSOs or the NRAs. As some of these new costs and investments opportunities are new, they represent a possible risk, as the added value and resulting benefits are often uncertain. Regulatory frameworks have traditionally existed to avoid risky investments from the network monopolies. However, the energy transition and the progress toward smarter distribution grids calls for a framework that supports innovation. EU regulators are in the process of understanding how to best create regulations that accomplish these goals ${ }^{23}$. In the EU we already have innovation stimulus in place for Slovenia, Greece, Ireland, Austria, Denmark, Finland, Slovakia, Italy, Portugal, France, and the United Kingdom. All these countries have a regulatory framew ork that follows either a hybrid or incentive model, except for Greece that applies a cost-based approach ${ }^{21,23}$.

\footnotetext{
a High concentration, for Member States in which one DSO is responsible for over $99 \%$ of the distributed power. Medium concentration, for Member States in which one DSO has a dominant position with over $80 \%$ of the distributed power, or alternatively when three of the largest DSOs in a Member State are responsible for over $60 \%$ of the distributed power. Low concentration, for Member States in which the three largest DSOs are responsible for less than $50 \%$ of the distributed power 17,21 .

${ }^{b}$ Cost based regulation models ensure the DSO collects its investment and operational costs, plus an authorised rate of return. Incentive based regulation gives DSOs the possibility to enhance profits in case certain performance criteria is met ${ }^{43}$. Hybrid regulatory approaches combine aspects of cost based and incentive regulation, of ten using a cost based approach for capital expenditures, and an incentive approach for operational expenditures 17,21,24,43.
} 


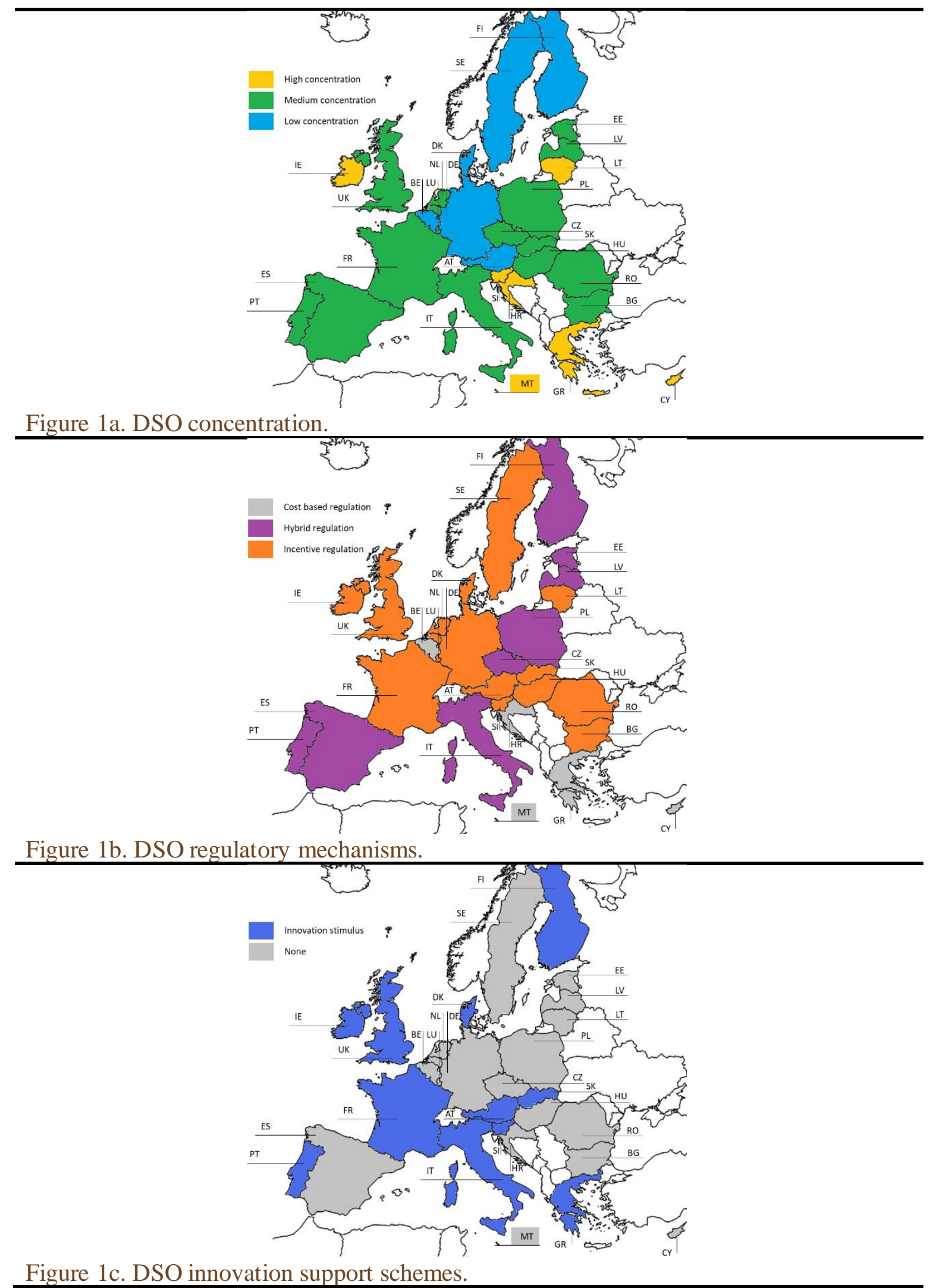

Figure 1. Electricity distribution industry in the EU. 
Sources: ${ }^{17,21,23-25}$

The complexity of the electricity sector market transformation efforts under the Energy Union and its impact on DSOs requires a more detailed understanding and analysis of policy alternatives to support a shift toward smarter and more sustainable distribution grids.

\section{Research methodology}

We apply a Policy Delphi method to examine policy alternatives for a transition to smart distribution grids in the EU. This technique supports foresight analysis and establishes a framework through which policy alternatives can be assessed based on experts knowledge ${ }^{26}$. As part of the family of Delphi techniques the Policy Delphi is implemented through an iterative expert elicitation process. Nevertheless, differing from traditional Delphi applications Policy Delphi studies are not designed to facilitate decision making and problem solving through consensus, but rather to generate as many perspectives on complex policy issues as possible ${ }^{27,28}$. In this context, policy issues have been described as any policy alternative for which different perspectives exist ${ }^{29,30}$. Moreover, it provides a flexible method for the analysis of policy issues in diverse fields related to technological innovation, public policy adaptation, and climate concerns ${ }^{31}$.

Our Policy Delphi was conducted through three rounds of expert consultation. Semistructured interviews with a small group of experts were conducted on the first round, to identify the topics and policy issues to be included in the Delphi questionnaires. The experts consulted in this first round included: DSOs, National Regulatory Authorities, and researchers and academics. The second and the third round consisted of online questionnaires through which experts evaluated and commented on policy alternatives. The questionnaire used in the second round was based on close ended policy alternatives, to obtain quantitative assessments from experts. The second questionnaire gave experts the opportunity to comment and give feedback on each of the presented statements. The expert selection and invitation approach aimed to engage a diverse group with experience and interest in contributing to smart grid development, electricity sector policies, and market design. Given our EU focus, all the invited experts were from European countries. The first questionnaire had 207 participating experts, and the second questionnaire 103. Participating experts represent a diverse set of stakeholders, as described in Table $3^{\mathrm{c}}$.

c Supplementary material Table A 1 provides detailed information on the region of origin of the participating experts. 
Table 3. Expert stakeholder categories.

\begin{tabular}{|c|c|c|c|c|c|}
\hline \multicolumn{2}{|c|}{ Stakeholder } & $\begin{array}{l}1^{\text {st }} \text { Policy } \\
\text { Delphi } \\
\text { Questionnaire }\end{array}$ & $\%$ & $\begin{array}{l}2^{\text {nd }} \text { Policy } \\
\text { Delphi } \\
\text { Questionnaire }\end{array}$ & $\%$ \\
\hline \multicolumn{2}{|c|}{ Distribution System Operator } & 85 & $41 \%$ & 38 & $37 \%$ \\
\hline \multicolumn{2}{|c|}{ Industry analysts and Consultants } & 85 & $13 \%$ & 10 & $10 \%$ \\
\hline \multicolumn{2}{|c|}{ Researchers and Academics } & 85 & $28 \%$ & 32 & $31 \%$ \\
\hline \multirow{8}{*}{ Other } & $\begin{array}{l}\text { Electricity Generation } \\
\text { Companies }\end{array}$ & 9 & $4 \%$ & 3 & $3 \%$ \\
\hline & Electricity Retail Companies & 3 & $1 \%$ & - & - \\
\hline & Electricity sector associations & 3 & $1 \%$ & - & - \\
\hline & Policy Maker & 2 & $1 \%$ & - & - \\
\hline & Regulator & 3 & $1 \%$ & 1 & $1 \%$ \\
\hline & $\begin{array}{l}\text { Transmission System } \\
\text { Operator }\end{array}$ & 6 & $3 \%$ & 3 & $3 \%$ \\
\hline & Other & 12 & $6 \%$ & 16 & $16 \%$ \\
\hline & Other Total & 38 & $18 \%$ & 23 & $22 \%$ \\
\hline \multicolumn{2}{|l|}{ Total } & 207 & $100 \%$ & 103 & $100 \%$ \\
\hline
\end{tabular}

The policy issues included in this study consist of statements presented for experts to evaluate. These statements represent alternatives in terms of DSOs business model adaptation, looking at how these are organised and what activities they conduct; and market design, by considering different policy alternatives shaping the electricity sector and DSOs role in it. The experts evaluated each policy alternative statement using Likert scales.

\section{Results}

We present a combination of quantitative policy alternative assessments with qualitative insights resulting from our expert's comments collected from the surveys. These results provide a more detailed perspective on policy alternatives related with the transition to smarter distribution grids.

The business model adaptation policy issues focused on exploring alternatives associated with DSOs business strategy, adaptation challenges, and associated tasks and responsibilities. We questioned our panel about "How should DSOs position themselves regarding business model and organizational innovation?". The results ind icate that limiting business strategy to the possibilities allowed by existing regulations represents a weak policy alternative, according to $81.6 \%$ of the panel, see Figure $2^{\mathrm{d}}$. The following panellist remark corroborates this:

"Current regulation is very conservative and might be limiting new market developments. One of the associated risks is related with separating the costs and benefits of the new market opportunities. Conservative regulations might concentrate all costs for DSO's whereas new start-up companies can reap in the profits by providing innovative services."

\footnotetext{
d The supplementary material provides policy alternatives assessment per stakeholder group as well as policy alternatives assessment per region.
} 


\section{[Distribution System Operator, Western Europe]}

Adding to the perspective of the limitations of existing regulation, one expert argued in favour of DSOs internal capabilities and how these can support them in redirecting their business strategy into new fields, as follows:

"DSOs have good capabilities to perform tasks around flexibility services, energy storage and electric vehicle charging infrastructure. Even though the European Commission does not like to see DSOs actively acting and owning these kinds of units they are best equipped for it."

\section{[Distribution System Operator, Northern Europe]}

In line with this, the panel emphasized the need for DSOs to contribute to a regulatory framework that supports changes in business strategy and is ready for a more flexible distribution system, as observed in the following remark:

"DSO should seek to influence regulators options by stating their points of view according to the strategy they find more correct, both from the perspective of the company's health, which is of public interest, and from the perspective of society at large and consumers."

[Researchers and Academics, Southern Europe]

In view of the challenges associated with business model adaptation we questioned our panel on "How do you perceive the difficulty of DSOs adaptation to a changing electricity sector?". Here $83.5 \%$ of the experts considered that DSOs will face difficulties in adapting their role in a timely manner (see Figure 2). This adaptation has often been associated with the transition to smart grids ${ }^{32,33}$, and more recently to the electricity distribution industry digital transformation ${ }^{34,35}$. The extent of these ad aptation challenges was discussed by one expert as follows:

"Digital transformation is more than digitalization, and calls for doing different things and not just the same things in a different way. This means new skills, even at the board level, and cross sectoral knowledge (e.g. information and energy networks) that calls for a disruptive approach that is out of the DNA of most DSOs, starting by the decision-making process, usually conservative, too centralized and time consuming, not compatible with a fast-changing world."

[Distribution System Operator, Southern Europe]

Aspects related to DSO structure and new entrants were also discussed by our experts, in this way:

"Being (natural or not) monopolies (depending on their size), DSOs have a considerable inertia to innovate especially when compared to the fastmoving sector of ICT."

[Researchers and Academics, Southern Europe]

The integration of new technologies to support the transition to smarter distribution grids was considered a difficult adaptation challenge by $62.1 \%$ of our experts (see Figure 2 ). One 
of the experts connected this difficulty with the lack of incentives to do so, as presented below:

"For us this is difficult because there are no incentives today to do that."

[Distribution System Operator, Northern Europe]

One of our Policy Delphi participants commented on the approach to technological evolution at the DSO level, skewed toward incremental rather than disruptive innovation:

"DSO tend to adopt incremental rather than disruptive technologies. So, new adopted technologies will tend to be a step behind of limits or even possibilities."

[Distribution System Operator, Southern Europe]

Additionally, one of our panellists discussed the risk of stranded investments and how these can make technological adaptation more difficult:

"There is always a risk of making wrong technology choices leading to stranded investments. However, this should be manageable and might not affect the fundamentals of the DSOs business model. The risk of financing possible stranded investments (i.e. infrastructure that turns out not to be needed or that will be outdated before amortisation) is of regulatory (and maybe political) nature and could vary from country to country."

[Researchers and Academics, Western Europe]

For the integration of new business processes and management practices $62.1 \%$ of participating experts considered it to be a difficult adaptation challenge (see Figure 2). The complexity of implementing new business processes and how these may impact connected consumers was discussed by the experts:

"DSOs can adapt new processes if they are paid to do so. It is very easy to have extremely complicated processes which have very high costs for the DSO, where the benefits accrue to a small subsection of customers but where the costs are socialised over the majority. This then leads to dissatisfaction amongst the bulk of customers making further work very difficult."

\section{[Distribution System Operator, Western Europe]}

Our experts also framed this issue within the potential transition of role by the DSO and how regulation influences this, discussed as follows:

"This is what I find particularly difficult with the changing role of DSOs (from network operators to data manager, market facilitator, etc.) and this is the part most dependant on regulation."

[Researchers and Academics, Western Europe]

Shifting from the broader policy alternatives on business strategy and adaptation challenges, we queried our experts if "In the future DSOs should be involved in the following activities?" and presented them with different activities. These were designed to provide more clarity in terms of the role of the DSO in the future, which is ultimately 
shaped by the tasks and responsibilities included in their operations $36,37,7$. In this context, smart meter ownership was considered a strong policy alternative by $70.9 \%$ of the experts (see Figure 2). This result is emphasised by the following comment:

"Supplier switching is much easier when the DSO owns the smart meter, given its neutral market facilitation role. Also, the DSOs need the smart meters data to optimize the grid."

[Distribution System Operators, Northern Europe]

The following feedback provides an additional perspective on the consumer as a possible smart meter owner:

"The owner of the smart meter should be either the DSO or the client. In any case, the client should be the owner of the measurements and the DSO should be allowed to read aggregated values for billing purposes and check detailed values for fraud prevention."

[Researchers and Academics, Southern Europe]

Resulting from the increased diffusion of smart meters, in combination with more sensors connected to electricity distribution grids, the resulting data could be leveraged toward the development of added value services by other market players ${ }^{38}$. Having DSOs as managers of a data marketplace platform was considered a strong policy alternative by $75.7 \%$ of our experts' panel (see Figure 2). Our experts supported this position through the following:

"Acting as data hubs DSO are in the best position to assure compliance with the European General Data Protection Regulation in terms of data privacy."

[Distribution System Operator, Southern Europe]

In line with the previous comment, the following remark further emphasises the role of DSOs in enabling new markets players:

"This is a role which is more appropriate for DSOs. They might be better off as enablers of other market players which are entering the distribution services market."

[Industry analysts and Consultants, Eastern Europe]

Energy efficiency and energy savings are an important pillar of the European electricity sector sustainability transition ${ }^{39,40}$. In this regard, $67 \%$ of our experts expressed that DSOs should provide energy efficiency and energy savings advice to end-users (see Figure 2). Despite the general position of the panel on the relevance of DSOs as promoters of energy efficiency, the following comments indicate the importance of this type of activity being performed by other market players:

"A DSO should not be involved in this area. It should simply provide a platform (i.e.: network) on which others will operate a market for such services. There is no reason a DSO will have better skills in this area than others, so why would it find it attractive?"

[Distribution System Operator, Western Europe] 
The growing attractiveness and diffusion of electric vehicles creates the need to deploy electric vehicle charging infrastructure that can support existing electric vehicle owners. Our panel considered that DSOs should be electric vehicle infrastructure owners, with $45.6 \%$ of support as a strong policy alternative (see Figure 2). For this policy issue our experts expressed the following views:

"DSOs should own the cables and wires to the chargers, but the chargers should be leased to EV charge companies on a franchise/licence basis. This allows technological competition at charging point level. This leads also to reduced entry barriers as DSOs make the initial investments."

[Distribution System Operator, Western Europe]

The following expert view brings to the discussion the possible complementarities between DSOs, electric vehicle loads, and electric vehicle charging infrastructure operators:

"DSOs may foster the deployment but not the competition toward the best electric vehicles charging infrastructure. Electric vehicles for rent, autonomous driving e-Cabs, etc., (basically any EV-infrastructure you can think of) shall be offered by independent competing companies/enterprises, i.e., customers of DSOs. However, DSOs shall be allowed to use EV batteries and EV charging facilities for grid stabilising (smart charging), paying an appropriate compensation to the EV infrastructure owner, which shall explicitly include the option to fund the charging hardware (i.e. buffer batteries)."

[Anonymous expert, Stakeholder category: n.a.]

Distributed electricity generation units connected to the grid are also increasing, and their adequate integration in the electricity system calls for changes on how infrastructure is planned and operated ${ }^{16}$. In line with this $73.8 \%$ of our experts considered the management of distributed generation units by DSOs, as a strong policy alternative (see Figure 2). A perspective on when should DSOs manage distributed generation is expressed in the expert comment below:

"DSOs should manage distributed generation as much as TSOs manage transmission-level generation. The main driver for distributed generation management should be local markets, but DSOs should guarantee the correct operation of the system, which implies having a certain degree of control on all producers and consumers connected to the corresponding distribution network."

[Researchers and Academics, Southern Europe]

Separation of electricity distribution and electricity retail activities took place as part of the market restructuring process leading to liberalisation ${ }^{18,41,42}$. As a result, electricity retail is forbidden for unbundled DSOs, which operate as neutral market facilitators. Nonetheless, we presented this activity as a future possibility to understand our panels' perspectives in having distribution and retail combined. $81.6 \%$ of our experts considered this a weak policy alternative (see Figure 2). The following comments corroborate this: 
"There is no need for DSOs to be involved in this area. Electricity retail is more of a fast-moving consumer good with short timescales, low skills base and small profit margin. DSO is 40-year time scale, higher margin, higher risk and much higher skill base."

[Distribution System Operator, Western Europe] 


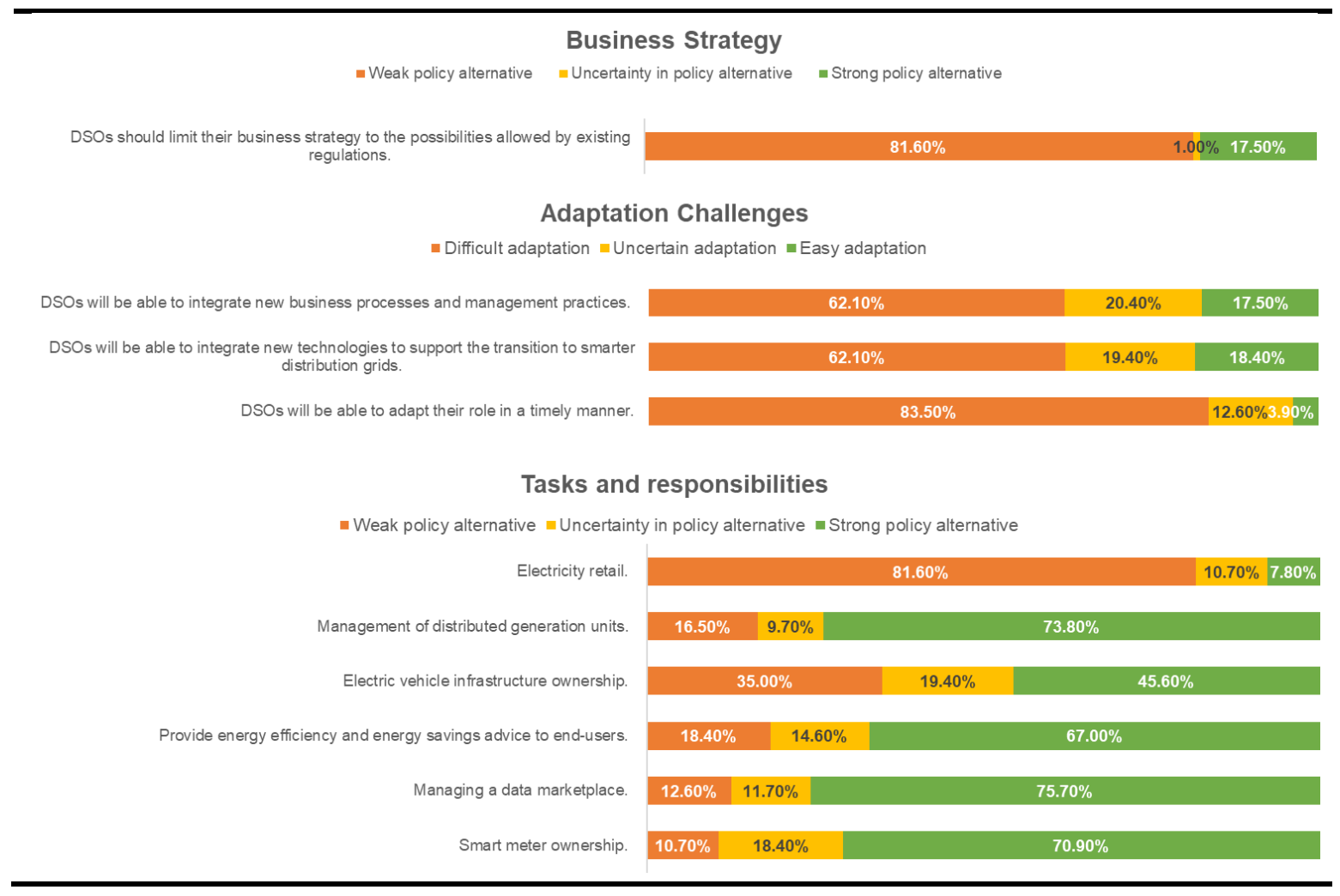

Figure 2. Business model adaptation policy issues.

On the topic of market design, we asked our panel "How important are the following policyoriented actions in the ongoing DSOs transition?". In terms of Member State policy action, we asked our experts if the role of the DSOs should only be specified at the Member State level, allowing each country to establish its role to fit the specific context. This was considered a strong policy alternative by $42.7 \%$ of our experts (see Figure 3 ). Experts point to the local and national role of DSOs in supporting this policy alternative. Complementing this perspective, one panellist expands on this policy alternative indicating the need to establish DSOs roles at the EU level:

"This is important; however, it should not be limited at the Member State level only. Harmonisation of the DSO's role at EU level should exist and it will prove necessary in the (near) future, particularly with the advent of even more increasing distributed energy resources, electric vehicles, and active consumers and prosumers."

[Researchers and Academics, Western Europe]

Considering the European Union level policy alternatives, we prompted our experts in terms of the role of the unbundling threshold of 100,000 consumers, and if it should be reviewed given the need for DSOs to innovate and adapt. $49.5 \%$ of the experts evaluated this as an uncertain policy alternative (see Figure 3). One of our experts mentioned the need to remove this threshold and unbundle all DSOs:

"In my opinion the threshold should be removed, and the unbundling requirements should be applied on all DSOs."

[Distribution System Operators, Northern Europe]

The following expert comment refers to the quality of applying a quantity based criterion: 
"Numbers are never a good separation criterion; any number is equally poor."

[Anonymous expert, Stakeholder category: n.a.]

The transition toward smart distribution grids encompasses new technologies, new processes, and the need for new regulatory approaches. Considering this we asked our panel if a new regulatory body should be established focusing on the transition to a smarter grid framework, with a strategy and incentives for DSOs to innovate. This was referred to as a strong policy alternative by $62.1 \%$ of the experts (see Figure 3 ). The following comment discusses the importance of innovation supportive regulation, and the possibilities for expanding existing regulators roles, rather than establishing a new stakeholder:

"Regulation establishing a strategy for DSOs is important, and may need incentives for fulfilling its objectives. Perhaps it is not necessary to establish a new regulatory body, and this can be done by existing entities."

[Researchers and Academics, Southern Europe]

In concluding our Policy Delphi process, we asked our experts "When will DSOs fully evolve toward active network managers?", with the goal to understand electricity distribution transition trajectories. In this context a DSO acting as an active network manager incorporates the full spectrum of smart grid capabilities, managing system flexibility as part of its operations ${ }^{38}$. Our experts indicated that both small DSOs (Less than 100,000 connected consumers), and large DSOs (Unbundled, with over 100,000) will transition to active network managers between 2021 and 2030 , with $76.7 \%$ of expert's support (see Figure 4).

Across topics we obtained expert insight regarding the extent to which DSO scale influences their ability to adapt and transition to new roles. Table 4 provides a synthesis of our panel perspectives from which we observe that adaptation challenges affect DSOs across scales. However, smaller DSOs are perceived as being better positioned to integrate new technologies, business processes, and evolving their overall role. 


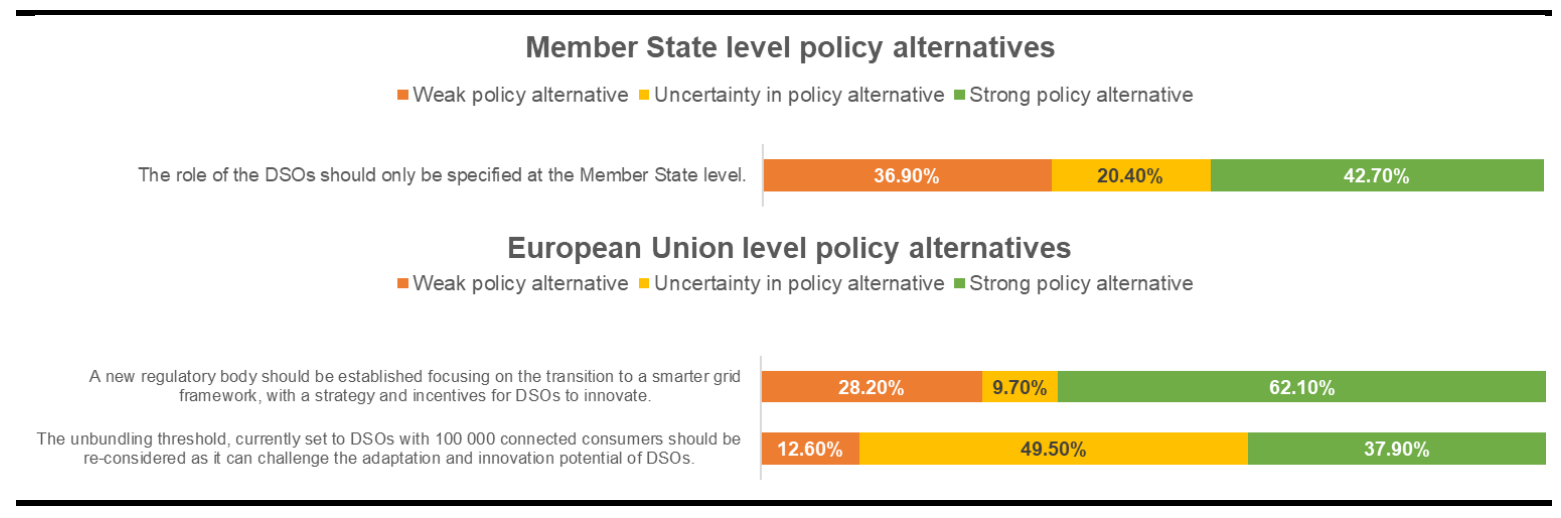

Figure 3. Business model adaptation policy issues.

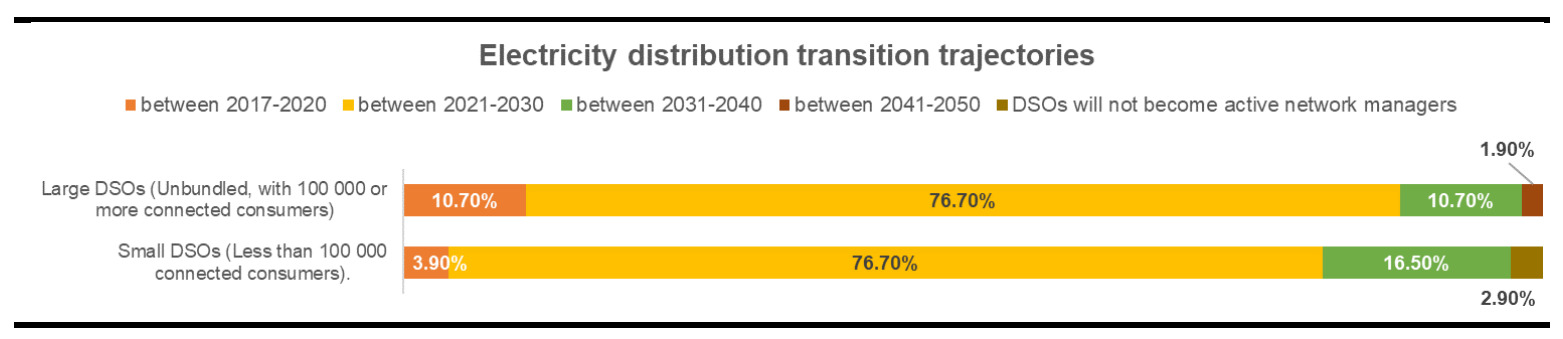

Figure 4. Business model adaptation policy issues. 
Table 4. Adaptation and DSO scale.

\begin{tabular}{|c|c|c|c|c|}
\hline \multirow{3}{*}{ Adaptation } & \multicolumn{4}{|c|}{ DSO Scale } \\
\hline & \multicolumn{2}{|c|}{ Small DSO (under 100,000 connected consumers) } & \multicolumn{2}{|c|}{ Large DSO (above 100,000 consumers) } \\
\hline & Weaker adaptation challenges & Stronger ad aptation challenges & Weaker adaptation challenges & Stronger ad aptation challenges \\
\hline $\begin{array}{l}\text { General } \\
\text { adaptation }\end{array}$ & & $\begin{array}{l}\text { "Adaptation will be difficult for } \\
\text { the small electricity } \\
\text { distributors." } \\
\text { [Transmission System } \\
\text { Operator, Southern Europe] }\end{array}$ & & $\begin{array}{l}\text { "DSOs are big and slow rather that } \\
\text { small and fast market participants, and } \\
\text { as such they cannot adapt quickly, if they } \\
\text { can at all. And if they should at all. } \\
\text { Newcomers from the IT sector will enter } \\
\text { the distribution services market much } \\
\text { faster and much more interested in } \\
\text { providing new and additional services } \\
\text { than DSOs." } \\
\text { [Distribution System Operator, Eastern } \\
\text { Europe] }\end{array}$ \\
\hline $\begin{array}{l}\text { Technological } \\
\text { adaptation }\end{array}$ & $\begin{array}{l}\text { "It may be easier for smaller } \\
\text { DSOs operating on newly } \\
\text { constructed networks." } \\
\text { [Researchers and Academics, } \\
\text { Southern Europe] }\end{array}$ & & $\begin{array}{l}\text { "There are no real problems } \\
\text { for larger, often technically } \\
\text { outstanding DSOs, but most } \\
\text { DSOs are not like that." } \\
\text { [Distribution System } \\
\text { Operators, Southern Europe] }\end{array}$ & $\begin{array}{l}\text { "It would be much complex for larger } \\
\text { DSOs. It is also a matter of voltage } \\
\text { level: the transition to smarter } \\
\text { distribution grids is easier in Medium } \\
\text { Voltage networks, but is quite } \\
\text { challenging for Low Voltage networks." } \\
\text { [Researchers and Academics, Southern } \\
\text { Europe] }\end{array}$ \\
\hline $\begin{array}{l}\text { New business } \\
\text { processes }\end{array}$ & $\begin{array}{l}\text { "This is less technology- } \\
\text { dependent, smaller DSOs can } \\
\text { be more than capable of } \\
\text { adaptation, possibly even } \\
\text { better than large DSOs." } \\
\text { [Distribution System Operator, } \\
\text { Southern Europe] }\end{array}$ & & & \\
\hline
\end{tabular}




\begin{tabular}{lll}
\hline & "Some small are quite & \\
& $\begin{array}{l}\text { innovative and they can make } \\
\text { money given current }\end{array}$ & "Small DSOs need to be better \\
& regulation." & considered by the regulation \\
Transition to & [Anonymous expert, & from now on, and will be ready \\
active & Stakeholder category: n.a.] & in a few years to become active \\
network & "Small are more agile and can & network managers." \\
managers & adopt, but evidently there will & [Researchers and Academics, \\
& be laggards among them." & Southern Europe] \\
& [Anonymous expert, & \\
& Stakeholder category: n.a.] & \\
\hline
\end{tabular}




\section{Discussion}

In terms of business model adaptation we highlight the importance of a shift on DSOs business strategy, which should not be hindered by existing regulatory frameworks. Our panel emphasised the need for DSOs to be proactive in contributing to the design of innovation supportive regulations. DSOs and regulators were identified as being conservative and having significant inertia to change. In this context, the DSOs skills set, and their historical role focused mostly on electricity distribution were pointed as contributors to adaptation challenges. Moreover, the potential space for new entrants to provide innovative services vis-à-vis DSOs evolving into new business models that could provide those services was also identified as a factor contributing to a more challenging adaptation. In addition, technology adaptation difficulties increase given the lack of innovation supportive regulatory frameworks, and the DSOs incremental approach to innovation.

Our results contribute also to an understanding of the tasks and responsibilities to be performed by DSOs in the future. Smart meters are positioned as a strategic asset for DSO ownership, associated with their neutral market facilitation role. Building on the growing levels of accessible data resulting from smart meters and other sensors embedded in distribution grids. The possibility for DSOs to operate as a data hub was also considered as an opportunity for the future.

Tasks associated with the provision of energy efficiency services and ownership of electric vehicle infrastructure were considered as less adequate for DSOs, given the possibilities of competitive market players to perform better in these roles. This is in line with the recent proposals for market design on the scope of the Clean Energy for All Europeans policy package which indicate that DSOs should only be involved in ownership, development, or management of recharging points when either no market player has expressed interest, or when the regulators allow for it ${ }^{12}$.

In terms of market design experts highlight the importance of focusing on the national characteristics of electricity systems, and local needs, which can sometimes be overlooked if a common EU-level DSO role is established. Moreover, the impact of DSOs scale on adaptation and transition to new roles was discussed by our experts. Our results position smaller DSOs as more flexible and adaptable to the changes impacting the electricity distribution industry.

Understanding how electricity distribution business model adaptation can be supported should be considering by EU policy makers. Future policy developments should provide guidance on new service offerings, and organisational structure for smart electricity distribution. Moreover, the evolution on the DSO role, now incorporating access to increased volumes of collected data, and monitoring capabilities, can contribute to the facilitation of new services, and markets. Policy makers should consider how a data intensive future can contribute to increasing electricity distribution quality of service and innovation that benefits European electricity consumers.

Our findings highlight the relevance of the DSO as a facilitator of services that can be provided in competitive markets. This should be taken into account in future policies to ensure that DSOs can support market development, and facilitate innovative services. 


\section{Conclusions}

The goal of this study was to contribute to the ongoing policy debate related to identifying business model and market design alternatives for the transition of DSOs to a smart grid framework. The Policy Delphi method applied contributed to this goal by providing a structured communication and data collection process through which 207 European experts were engaged.

Our results reinforce the need for a complementary approach, including a more proactive role of DSOs in shaping future electricity sector market design and their potential role in it. In addition to a regulatory framework that supports innovation and deployment of smart grid technologies, and new business models. Our study indicates also the need for DSOs to continue operating as neutral market facilitators. This is observed through our panellists' preference for DSOs to focus on activities where they can facilitate new markets and players, rather than taking tasks and responsibilities that can be best performed by competitive market participants.

The strength of this study is related with the geographical and stakeholder category diversity of the group of experts. The outcomes of this study are limited by the scope of the policy alternatives created in the initial stage of the research design process. Future work includes expanding the range of policy issues considered, as well as developing Member State focused analyses that can be contrasted with the EU level approach of this study. 


\section{Acknowledgements}

The authors acknowledge the Portuguese National Foundation for Science and Technology (FCT) for supporting this work through the Doctoral Grant PD/BD/105841/2014, awarded on the framework of the MIT Portugal Program funded through the POPH/FSE. Additionally, this work has been partially supported by FCT under project grant: UID/MULTI/00308/2013, and SAICTPAC/0004/2015-POCI-010145-FEDER-016434, as well as by the Energy for Sustainability Initiative of the University of Coimbra.

\section{References}

1. European Commission. Europe 2020 - A strategy for smart, sustainable and inclusive growth. Brussels, 2010.

2. European Commission. A policy framework for climate and energy in the period from 2020 to 2030. Brussels, 2014.

3. European Commission. Energy Roadmap 2050, 2011.

4. IEA. Technology Roadmap - Smart Grids. Paris, 2011.

5. IEA. Smart grids in distribution networks: Roadmap development and implementation. 2015.

6. Ruiz-Romero S, Colmenar-Santos A, Mur-Pérez F, et al. Integration of distributed generation in the power distribution network: The need for smart grid control systems, communication and equipment for a smart city - Use cases. Renew Sustain Energy Rev 2014; 38: 223-234.

7. CEER. The Future Role of DSOs. A CEER Public Consultation Paper. Brussels, 2014.

8. Shomali A, Pinkse J. The consequences of smart grids for the business model of electricity firms. J Clean Prod 2016; 112: 3830-3841.

9. Shah M, Valenzuela JM, Mora Beltran HA, et al. Clean Restructuring: Design Elements for Low-Carbon Wholesale Markets and Beyond. 2016.

10. European Commission. A Framework Strategy for a Resilient Energy Union with a Forward-Looking Climate Change Policy. Brussels, 2015.

11. European Commission. Clean Energy for All Europeans. Brussels, 2016.

12. European Commission. Directive of the European Parliament and of the Council on common rules for the internal market in electricity. Brussels, 2017.

13. European Commission. Regulation of the European Parliament and of the Council on the internal market for electricity. Brussels, 2017.

14. European Commission. Regulation of the European Parliament and of the Council establishing a European Union Agency for the Cooperation of Energy Regulators. Brussels, 2017.

15. European Commission. Towards an Integrated Strategic Energy Technology (SET) Plan: Accelerating the European Energy System Transformation. Brussels, 2015.

16. ETIP SNET. Final 10-year ETIP SNET R\&I roadmap covering 2017-26. Brusels, 2016.

17. Eurelectric. Power distribution in Europe - Facts and figures. Brussels, 2013. 
18. European Union. Directive of 2009/72/EC of the European Parliament and of the Council of 13 July 2009 Concerning Common Rules for the Internal Market in Electricity and Repealing Directive 2003/54/EC.

19. CEER. Status Review on the Implementation of Distribution System Operators' Unbundling Provisions of the 3rd Energy Package. Brussels, 2016.

20. Meeus L, Hadush S. The emerging regulatory practice for new businesses related to distribution grids. 2016; 1-6.

21. Cambini C, Meletiou A, Bompard E, et al. Market and regulatory factors influencing smart-grid investment in Europe: Evidence from pilot projects and implications for reform. Util Policy 2016; 40: 36-47.

22. Pérez-Arriaga IJ. Regulation of the Power Sector. London: Springer London. 2013.

23. Eurelectric. Innovation incentives for DSOs - a must in the new energy market development. Brussels, 2016.

24. Eurelectric. Electricity Distribution Investments: What Regulatory Framework Do We Need?. Brussels, 2014.

25. Ernst \& Young. Mapping power and utilities regulation in Europe. 2013; 1-40.

26. Linstone HA, Turoff M. Delphi: A brief look backward and forward. Technol Forecast Soc Change 2011; 78: 1712-1719.

27. Franklin KK, Hart JK. Idea Generation and Exploration: Benefits and Limitations of the Policy Delphi Research Method. Innov High Educ 2006; 31: 237-246.

28. Landeta J. Current validity of the Delphi method in social sciences. Technol Forecast Soc Change 2006; 73: 467-482.

29. Turoff M. The design of a policy Delphi. Technol Forecast Soc Change 1970; 2: 149-171.

30. Linstone H, Turoff M. The Delphi Method - Techniques and Applications. Addison-Wesley Educational Publishers Inc, 2002.

31. Loë RC, Melnychuk N, Murray D, et al. Advancing the State of Policy Delphi Practice: A Systematic Review Evaluating Methodological Evolution, Innovation, and Opportunities. Technol Forecast Soc Change 2016; 104: 78-88.

32. Clastres C. Smart grids: Another step toward sompetition, energy security and climate change objectives. Energy Policy 2011; 39: 5399-5408.

33. Lund H, Andersen AN, Østergaard PA, et al. From electricity smart grids to smart energy systems - A market operation based approach and understanding. Energy 2012; 42: 96-102.

34. ETIP SNET. The Digital Energy System 4.0. Brussels, 2016.

35. Council of the European Union. Tallinn e-Energy declaration. Brussels, 2017.

36. CEER. The Future Role of DSOs. A CEER Conclusions Paper. Brussels, 2015.

37. ACER and CEER. The Role of the DSO. Brussels, 2017.

38. Oosterkamp P van den, Koutstaal P, Welle A van der, et al. The role of DSOs in a Smart Grid environment. Amsterd am, 2014.

39. European Commission. A Framework Strategy for a Resilient Energy Union with a Forward-Looking Climate Change Policy. Brussels, 2015.

40. European Commission. Clean energy for all - The new Energy efficiency measures. Brussels, 2016.

41. European Union. Directive 96/92/EC of The European Parliament and of the 
Council of 19 December 1996 concerning common rules for the internal market in electricity, 1996.

42. European Union. Directive 2003/54/EC of The European Parliament and of the Council of 26 June 2003 concerning common rules for the internal market in electricity and repealing Directive 96/92/EC, 2003.

43. Cambini $\mathrm{C}$, Rondi L. Incentive regulation and investment: evidence from European energy utilities. J Regul Econ 2010; 38: 1-26. 